\title{
ISOLAMENTO E SELEÇÃO DE BACTÉRIAS ENDOFÍTICAS E RIZOSFÉRICAS DE CACTÁ CEAS EM MEIO SOB ESTRESSE HÍDRICO
}

\author{
Clayton dos Santos Silva ${ }^{1 *}$, Érica Lívea Ferreira Guedes ${ }^{1}$, Micheline Thais dos Santos ${ }^{1}$, Yamina Coentro Montaldo ${ }^{1}$, \\ José Ubaldo Lima de Oliveira ${ }^{1}$, Tania Marta Carvalho dos Santos ${ }^{1}$
}

${ }^{1}$ Laboratório de Microbiologia, Centro de Ciências Agrárias - Universidade Federal de Alagoas/UFAL

*clayton@live.com.pt

\section{INTRODUÇÃO}

A água é imprescindível para a manutenção da vida e essencial para a produção de alimentos, contudo devido as constantes adversidades climáticas e o mau uso desse recurso, o setor agropecuário brasileiro vem sofrendo graves consequências, limitando a atividade no país. Durante o processo evolutivo, as xerófitas (plantas que se adequaram e desenvolveram mecanismos ao longo do tempo, que permitiram viver em ambientes secos e quentes), adquiririam mecanismos de tolerância a escassez de água no ambiente em que estão dispostos, dentre eles, o fechamento dos seus estômatos para reduzir a perda de água para o meio, poré $\mathrm{m}$, ao mesmo tempo que as cactáceas evoluíram, os microorganismos associados a essas plantas também sofreram mudanças que proporcionaram que as mesmas tolerassem a ambientes com atividade hídrica restrita (KAVAMURA et al, 2013).

Dentre estes mecanismos podemos citar: a produção de EPS (exopolissacarídeos), produção de biofilme. Estes mecanismos auxiliam na colonização do sistema radicular por micro-organismos que conferem tolerância a estresses ambientais, como o salino, as variações de temperatura, produção de ácido hialurônico, fazendo com que a planta resistam a ambientes com atividade hídrica restrita. Objetivou-se prospectar, selecionar bactérias endofíticas e de solo da rizosfera de cactáceas da Caatinga com capacidade de crescimento em meio com reduzida atividade de água.

\section{MATERIAIS E MÉTODOS}

Foram realizadas coletas de solo rizosférico $(10 \mathrm{~cm}$ de profundidade da superfície) e parte aérea de xerófitas nas cidades de Piranhas e Olho D'Água do Casado, ambas localizadas no sertão do estado de Alagoas (Figura 1). Após a coleta, as amostras foram armazenadas em sacos de papel apropriados, para a melhor conservação do material.

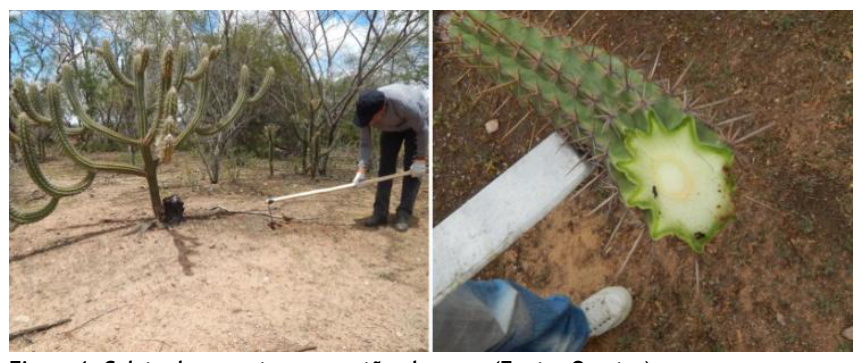

Figura 1. Coleta das amostras no sertão alagoano (Fonte: 0 autor).
Para o isolamento das bactérias rizosféricas, cerca de $1 \mathrm{~g}$ de solo foi transferido para Erlenmeyers contendo $10 \mathrm{~mL}$ de tampão (ARAÚ JO et al., 2002). A solução foi submetida a agitação por 1 hora. Após agitação, foram realizadas diluições seriadas de $10^{-2}$ a $10^{-5}$ seguida da retirada de alíquotas de $100 \mu \mathrm{l}$ das diluições adequadas, semeadas em meio Tryptone Soya Agar (TSA) (10\%), sendo o nú mero de unidades formadoras de colônias estimadas. Para isolamento das bactérias do período de seca, após obtenção dos isolados em TSA (10\%), estes, foram semeados em meio com três concentrações diferentes de sorbitol, produzindo valores de $\mathrm{AW}$ correspondentes a $0,957,0,897$ e 0,807 , e incubados a $40^{\circ} \mathrm{C}$.

Os isolados bacterianos foram purificados pela técnica de estria composta, armazenados em meio TSA $(10 \%)$ em tubo de ensaio inclinados e posteriormente armazenados em tubos criogênicos de 2,0 $\mathrm{mL}$ contendo glicerol $50 \%$ a $18^{\circ} \mathrm{C}$.

Foram inoculados $5 \mu \mathrm{l}$ dos isolados bacterianos crescidos em meio Tryptone Soya Broth (TSB) (10\%) em discos de $5 \mathrm{~mm}$, em meio de cultura modificado de Guimarães et al. (1999), adicionado de $10 \%$ de sacarose. A produção de EPS foi caracterizada visualmente mediante medida do halo do EPS produzido, sendo + (pouca produç ão - halo de EPS $\leq 10 \mathrm{~mm} \varnothing$ ), ++ (média produção - halo de EPS de 10-14 mmØ) e +++ (ótima produção - halo de EPS $\geq 14 \mathrm{~mm} \emptyset$ ). A confirmação da produção de EPS, foi realizada pelo método quí mico, misturando uma alça de platina impregnada com a colônia em $2 \mathrm{~mL}$ de álcool etílico (PAULO, 2010). O ensaio se deu em delineamento experimental inteiramente casualizado em desenho fatorial com 3 repetições.

Posteriormente foram inoculados $100 \mu \mathrm{l}$ dos isolados bacterianos, crescidos em meio TSB em tubos de polipropileno com $900 \mu \mathrm{l}$ de meio TSB (10\%) adicionado de sorbitol $(0,03 \mathrm{M}, 0,06 \mathrm{M}, 0,30 \mathrm{M}$, $0,60 \mathrm{M})$. Após incubação a $40^{\circ} \mathrm{C}$ por 96 horas, o conteúdo de cada tubo foi homogeneizado e aferida a absorbância em espectrofotô metro a $600 \mathrm{~nm}$, para verificar o crescimento bacteriano. As cé lulas planctônicas foram removidas e cada tubo foi lavado três vezes com água destilada, seguida de adição de $1000 \mu \mathrm{l}$ de solução de cristal violeta em cada tubo. Após 15 minutos de incubação a temperatura ambiente, os tubos foram lavados novamente três vezes com água destilada (MONTALDO, 2016). A formação de biofilme foi quantificada mediante adição de

$1000 \mu \mathrm{l}$ de álcool etílico (95\%) em cada tubo para solubilização do cristal violeta incorporado à parede. A densidade óptica do corante solubilizado foi determinada em espectrofotômetro a $560 \mathrm{~nm}$. (O' TOOLE; KOLTER, 1998). 


\section{RESULTADOS E DISCUSSÃO}

As estirpes bacterianas obtidas, foram armazenadas em freezer no Laboratório de Microbiologia Agrícola do Centro de Ciências Agrá rias/UFAL, totalizando 42 estirpes bacterianas. Obteve-se maior porcentagem de bactérias de solo rizosférico $(59,52 \%)$, em relação as endofíticas $(40,43 \%)$ do total das estirpes. No que diz respeito ao município de origem das bactérias, $42,82 \%$ foram provenientes do município de Olho d'Água do Casado, em contrapartida, 57,15\% das estirpes, foram obtidas dos materiais coletados no município de Piranhas. Em relação ao crescimento em meio de cultura, obtevese a maior quantidade de isolados no meio com concentração de MANITOL de $285 \mathrm{~g} / \mathrm{L}$, sendo esse, das três concentrações analisadas, o que possui maior atividade de água (AW).

Após o período de incubação, os halos formados ao redor dos discos de papel foram medidos com o auxílio de um parquímetro digital, onde foi verificada a média de produção de cada estirpe, sendo os mesmos divididos em três grupos: de baixa, média e alta produção de EPS, onde + (pouca produção - halo de EPS $\leq 10 \mathrm{~mm} \emptyset)$, ++ (mé dia produção - halo de EPS de 10-14 mmø) e +++ (ótima produção halo de EPS $\geq 14 \mathrm{~mm} \varnothing$ ). A figura 2 ilustra a leitura dos testes qualitativos para produção de EPS, por meio do método de discos, sendo possível visualizar a produção de EPS pelas linhagens, por meio da formação de uma substância mucóide ao redor do disco, onde a ausência dessa substância caracteriza linhagens não produtoras.

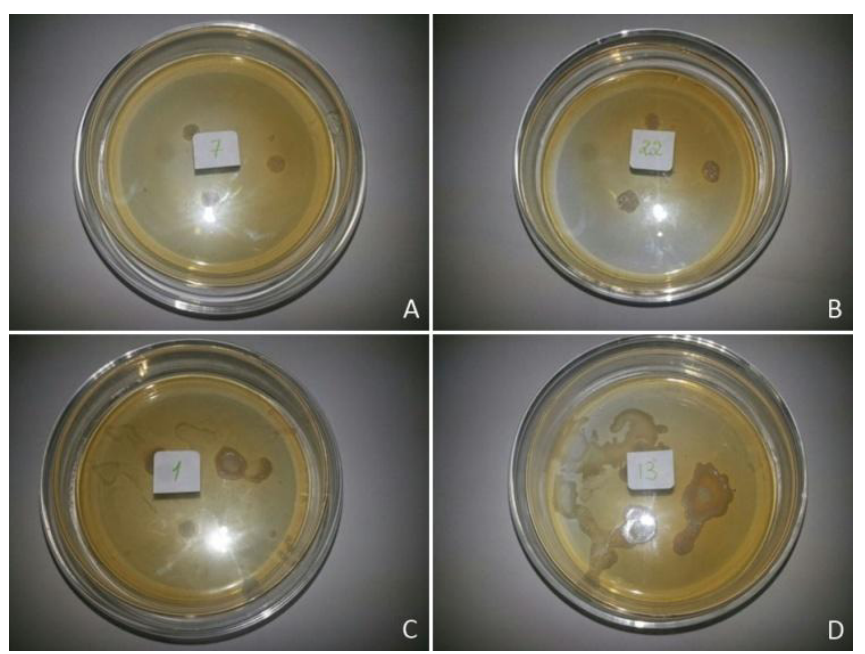

Figura 2. Diferentes producões de exopolissacarídeos (EPS) pelas estirpes bacterinas. (A) Isolado sem a formação de EPS; (B) Isolado com pouca produccão de EPS; (C) Isolado com média produção de EPS; (D) Isolado com alta produção de EPS (Fonte: 0 autor).

A confirmação da produção de EPS foi realizada pelo método quí mico. Observou-se que dos 11 isolados produtores de halo, a estirpe 4 não se caracterizou como produtor de exopolissacarídeos, pois as linhagens não produtoras de EPS ao serem misturadas em á Icool etílico ficam em suspensão, deixando o meio turvo. Já os exopolissacarídeos produzidos pelas linhagens, ao serem misturado com o álcool etílico, são precipitados (Figura 2).

Do total de estirpes bacterianas extraídas dos materiais vegetais coletados na Caatinga Alagoana, 23,80\% sintetizaram EPS em meio com atividade hídrica restrita, como ilustra a tabela abaixo.

0 resultado obtido difere do encontrado por MONTALDO (2016), cuja a maioria dos isolados obtiveram baixa produção de exopolissacarídeos (54\%), seguido por estirpes de média produção (42\%) e de pouca produção (4\%). ASHRAF et al (2005) avaliando bactérias produtoras de exopolissacarídeos, observaram que as mesmas promoveram mecanismos de tolerância ao estresse salino nas plantas de trigo inoculadas, melhorando as características fí sico-químicas do solo. A existência de bactérias halotolerantes que vivem associadas às plantas xerófitas, capazes de produzir EPS, ajudam diretamente na proteção deste vegetal contra diversos tipos de estresses, além de favorecer a melhoria na qualidade de solos salinos. (SILVA, 2014).

Tabela 1. Produção de exopolissacarídeos (EPS) das estirpes bacterianas do sertão alagoano. (+) Baixa produção de EPS; (++) Média produção de EPS; (+++) Alta produção de EPS.

\begin{tabular}{cc}
\hline Isolados & Produção de EPS \\
\hline 01 & ++ \\
02 & +++ \\
05 & ++ \\
06 & +++ \\
10 & +++ \\
13 & +++ \\
22 & + \\
28 & ++ \\
33 & + \\
35 & ++
\end{tabular}

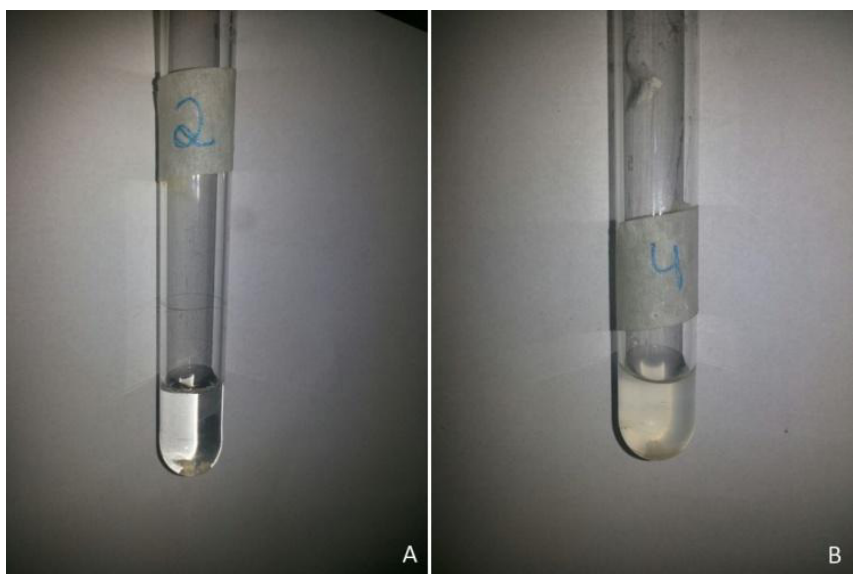

Figura 3. Confirmação de produção de EPS em álcool etílico. (A) Isolado produtor de EPS; (B) Isolado não produtor de EPS. (Fonte: 0 autor).

Para os testes de produção de biofilme, apenas 36 isolados foram avaliados, de modo a determinar os melhores parâmetros para as aferições. A presença de biofilme em superfície abiótica foi evidenciada pela formação de uma coloração violeta (Figura 4).

A formação de biofilme foi realizada em quatro concentrações de Sorbitol $(0,03 \mathrm{M}, 0,06 \mathrm{M}, 0,30 \mathrm{M}, 0,60 \mathrm{M})$, simulando diferentes níveis de estresse, entretanto a formação do mesmo não diferiu estatisticamente entre as diferentes concentrações, sendo os isolados comparados quanto sua capacidade de formação em meio com reduzida atividade hídrica.

Os resultados estão apresentados na Tabela 2, onde todos os isolados foram eficientes na formação de biofilme.

Do total de estirpes avaliadas, 11 obtiveram alta formação de biofilme, o que pressupõe a alta eficiência no que diz respeito a tolerância da bactéria, e a promoção de crescimento as plantas colonizadas pelas mesmas.

A formação de biofilme aparenta ser uma característica amplamente disseminada entre as bactérias, visto a positiva formação entre os isolados avaliados, auxiliando na colonização radicular, protegendo as células vegetais dos estresses ambientais, colaborando para a absorção de nutrientes presentes na solução do solo e na síntese de hormônios essenciais para o crescimento, 
desenvolvimento e estabelecimento dos vegetais no meio ambiente.

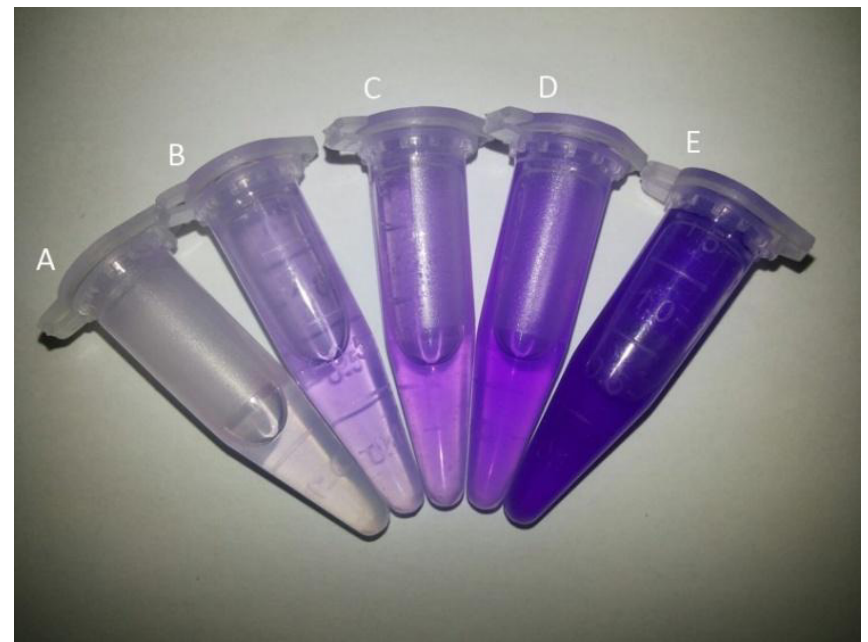

Figura 4. Formação de biofilme por isolados bacterianos em meio TSB contendo sacarose, baseada nos valores de absorbância obtidos em DO560 nm. (A) Controle

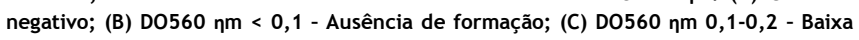
formação; (D) D0560 nm 0,2-1,0 - Média formação; (E) D0560 nm > 1,0 - Alta formaçã o de biofilme. (Fonte: 0 autor).

Tabela 2. Formação de biofilme em superfície abiótica por isolados bacterianos em meio TSB suplementado com 10\% de sacarose baseado nos valores de absorbância obtidos DO $560 \mathrm{~nm}$, segundo teste de Scott-Knott.

\begin{tabular}{|c|c|}
\hline Isolados & Biofilme \\
\hline 01 & $0.93195 \mathrm{~b}$ \\
\hline 02 & $1.54237 \mathrm{a}$ \\
\hline 03 & $1.76733 \mathrm{a}$ \\
\hline 04 & $0.91772 \mathrm{~b}$ \\
\hline 05 & $0.66498 \mathrm{~b}$ \\
\hline 06 & $1.23846 \mathrm{~b}$ \\
\hline 07 & $0.45400 \mathrm{~b}$ \\
\hline 08 & $0.77147 \mathrm{~b}$ \\
\hline 09 & $0.44752 \mathrm{~b}$ \\
\hline 10 & $0.83642 \mathrm{~b}$ \\
\hline 11 & $1.36859 \mathrm{a}$ \\
\hline 12 & $0.47149 \mathrm{~b}$ \\
\hline 13 & $0.88171 b$ \\
\hline 14 & $0.64888 \mathrm{~b}$ \\
\hline 15 & $0.32421 \mathrm{~b}$ \\
\hline 16 & $1.04795 \mathrm{~b}$ \\
\hline 17 & $0.87133 \mathrm{~b}$ \\
\hline 18 & $1.08905 \mathrm{~b}$ \\
\hline 22 & $0.80874 \mathrm{~b}$ \\
\hline 24 & $1.94397 \mathrm{a}$ \\
\hline 25 & $0.37360 \mathrm{~b}$ \\
\hline 26 & $1.97850 \mathrm{a}$ \\
\hline 28 & $1.86382 \mathrm{a}$ \\
\hline 29 & $2.47920 \mathrm{a}$ \\
\hline 30 & $0.58641 b$ \\
\hline
\end{tabular}

$0.92327 \mathrm{~b}$

$1.16353 b$

$0.76059 \mathrm{~b}$

$1.18309 \mathrm{~b}$

$0.84238 \mathrm{~b}$

$0.56398 \mathrm{~b}$

$0.37188 \mathrm{~b}$

$2.23971 \mathrm{a}$

1.77706 a

1.76699 a

$2.49460 \mathrm{a}$

*As médias seguidas pela mesma letra não diferem estatisticamente entre si.

\section{CONCLUSÕES}

De todos os isolados bacterianos avaliados, os que obtiveram melhor desempenho nas avaliações de mecanismos de tolerância ao estresse hídrico foram as estirpes 2 e 28, podendo posteriormente os mesmos serem utilizados para futuros testes de promoção de crescimento em plantas.

\section{REFERÊNCIAS}

ARAÚJO, W.L. et al. Manual de isolamento de microrganismos endofíticos. Departamento de Genética- Escola Superior de Agricultura "Luiz de Queiroz" - Piracicaba - ESALQ - USP. 2002.

ASHRAF, $M$. et al. Inoculating wheat seedlings with exopolysaccharide-producing bacteria restricts sodium uptake and stimulates plant growth under salt stress. Biology and Fertility of Soils, Springer, v. 40, n. 3, p. 157-162, 2005.

GUIMARÃES, D.P.; COSTA, F.; RODRIGUES, M.J.; MAUGERI, F. Optimization of dextran synthesis and acid hydrolis by surface response analysis. Brazilian Journal of Chemical Engineering, v. 16, p. 129-139, 1999.

KAVAMURA, V. N., SANTOS, S. N., DA SILVA, J. L., PARMA, M. M., Á VILA, L. A., VISCONTI, A., DE MELO, I. S. Screening of Brazilian cacti rhizobacteria for plant growth promotion under drought. Microbiological research, v.168, p.183-191, 2013.

MONTALDO, Yamina Coentro. Bioprospecção e isolamento de bactérias associadas à cana-de-açúcar (Saccharum officinarum L.) com características para a promoção de crescimento vegetal. 2016. $101 \mathrm{f}$. Tese (Doutorado em Rede Nordeste de Biotecnologia) Instituto de Química e Biotecnologia, Programa de Pós Graduação em Rede Nordeste de Biotecnologia, Universidade Federal de Alagoas, Maceió, 2016.

O'TOOLE, G.A.; KOLTER, R. Initiation of biofilm formation in Pseudomonas fluorescens WCS365 proceeds via multiple, convergent signalling pathways: A genetic analysis. Molecular Microbiology, v. 28, p. 449-461, 1998.

PAULO, E.M. Encapsulamento de Lactobacillus acidophilus por atomização em spray drying, utilizando exopolissacarídeos (EPS) produzidos por bactérias láticas. 2010. 222 p. Tese (Doutorado em Biotecnologia) - Universidade Estadual de Feira de Santana, Feira de Santana, 2010.

SILVA, F.G.; Bactérias halotolerantes associadas a plantas de Atriplex nummularia I. e sua inoculação em mudas. Dissertação (Mestrado em Produção Agrícola) - Universidade Federal Rural de Pernambuco - Unidade Acadêmica de Garanhuns, 2014. 